\title{
Minerals in drinking water available in Bangkok, Nakhon Nayok, and Chachoengsao
}

\author{
Veeravan Lekskulchai \\ Department of Pathology, Faculty of Medicine, Srinakharinwirot University, Sukhumvit 23, Wattana, \\ Bangkok 10110 Thailand \\ e-mail: veeravah@swu.ac.th
}

Received 4 Oct 2014

Accepted 30 Nov 2015

\begin{abstract}
In this study, drinking water from various sources in Bangkok and two other provinces in Thailand was collected, and its physical properties and mineral content were determined. Water from canals and dug wells contained diverse components making it turbid and coloured. Artesian water from the same province as canal and dug well water had similar mineral content, indicating that pollutants could spread thoroughly. The amount of iron detected in tap water varied from house to house, depending on its plumbing system since it came from corroded aged metal pipelines. The purity and mineral content of some bottled purified and mineral water were identical to that of the tap water. Furthermore, there was phosphate contamination in bottled water, probably from the bottle washing powder. Both local and imported bottled mineral water contained lower amounts of calcium and magnesium than expected, thus they might not be an effective mineral supplement. The high sodium content of sports drinks could make them harmful to health. The perception that bottled water is healthier than tap water should be reconsidered.
\end{abstract}

KEYWORDS: bottled, calcium, iron, magnesium, phosphate, sodium

\section{INTRODUCTION}

Drinking water is one of the essential needs for life. Naturally, plain water comes from either a natural surface or a ground source. A natural water source is rain, which in some areas is stored for drinking. Currently, in many parts of the world, drinking water comes from a public water system and commercial bottles. A survey has shown that people typically chose their drinking water based on their beliefs, perception, and prior experiences ${ }^{1}$. Due to limited information available, bottled water manufacturers use advertising to persuade their customers to buy their product as a healthy choice ${ }^{2}$. Furthermore, the bottled mineral water is promoted as a mineral supplement. Consequently, the demand for bottled water has consistently increased, followed by a growing concern about fraudulent claims regarding the water quality ${ }^{2-4}$.

There are various minerals in water; some have health benefits, but others pose health risks. Calcium and magnesium benefit health in preventing several diseases including cardiovascular diseases $^{5-7}$. Sodium is found considerably in daily foods and because of its undesired hypertensinogenic effect, its presence in drinking water is considered a health risk $^{8-10}$. Iron in drinking water results in disagreeable taste and rusty colour ${ }^{11}$. Phosphate in water is responsible for eutrophication as well, which poses significant environmental problems to water resources ${ }^{12-14}$. Phosphate, in phosphorus compounds, is found in fertilizers, pesticides, washing powders, or plastics. Thus phosphate in water comes from contamination of household or industrial wastewater and agricultural runoff. Information about the amounts of these minerals in drinking water can help consumers to choose water with properties that suits their needs and with a reasonable price.

In this study, the amounts of minerals in various kinds of drinking water from different locations in Thailand were determined. The aim was to compare physical appearances and mineral contents among drinking water from different sources available in three different provinces of Thailand.

\section{MATERIALS AND METHODS}

\section{Water sample}

Water samples were collected from the canals and dug wells in rural areas of Nakhon Nayok and Chachoengsao provinces during a rainy season. Samples of artesian water and rain were collected from these rural areas. Tap water samples were 
collected from urban areas in these provinces and from two different locations in Bangkok. Bottled water; three local brands of purified water, three local brands, and two imported European brands of mineral water, and two local brands of sport drink were purchased from a convenience store.

\section{Analysis}

Physical appearances: $\mathrm{pH}$, colour, turbidity, total dissolved solid (TDS) and hardness of water were investigated by APHA recommended standard procedures ${ }^{17}$. Electrolyte analyses: sodium, potassium, chloride, bicarbonate, calcium, and phosphate were analysed by VITROS 950 chemistry analyser (Ortho Clinical Diagnostics, Inc., Johnson \& Johnson, Rochester, NY). Iron and magnesium were analysed by BioSystems reagent \& instruments (BioSystems, S.A., Barcelona, Spain).

\section{RESULTS}

The physical properties of water samples are shown in Table 1, and their mineral contents in Table 2. Dug well and canal water had a mild to moderate stinky odour and brackish taste with fairly amounts of sediment. The artesian water was mild yellowish brown and brackish. Except for local brand \#1, all bottled mineral water was brackish. Both sport drinks were amber yellow, fragrant, and salty sweet.

\section{DISCUSSION}

Nowadays, drinking water is supplied in various forms. Surface water in a canal or a dug well is still consumed in some areas including rural and urban areas of Thailand. The water exposed to surrounding environment has unpleasant physical properties and diverse compositions derived from the geogenic, anthropogenic, and marine origins ${ }^{18,19}$. In this study, the canal and dug well water was coloured which is partly related to the iron contents. Nevertheless, its colour and TDS values indicate that there were soluble inorganic and organic salts or compounds dissolved in the water. Because the water has been exposed to agricultural fields and residential areas, it was unavoidably contaminated by pollutants and waste products. Sodium and chloride were detected in water from Chachoengsao province. Because the natural water sources in this province are linked to the gulf of Thailand via Bang Pakong River, $\mathrm{NaCl}$ in the water from this province results from tidal flushing of sea water ${ }^{20}$. Phosphate was detected in this water, which might have derived from chemical fertilizers and pesti-

Table 1 The physical properties of water.

\begin{tabular}{|c|c|c|c|c|c|}
\hline Source of water & $\mathrm{pH}$ & Colour unit & Turbidity NTU & TDS (mg/l) & Hardness (mg/l) \\
\hline Chachoengsao dug well & 7.28 & 35 & 45 & 420 & 259 \\
\hline Nakhon Nayok dug well & 7.21 & 45 & 50 & 340 & 161 \\
\hline Chachoengsao canal & 7.16 & 30 & 55 & 410 & 328 \\
\hline Nakhon Nayok canal & 7.22 & 25 & 50 & 350 & 60 \\
\hline Chachoengsao artesian water & 7.36 & 15 & 2 & 380 & 230 \\
\hline Nakhon Nayok artesian water & 7.32 & 25 & 2 & 270 & 53 \\
\hline Chachoengsao rain water & 6.64 & 10 & 1 & 170 & 66 \\
\hline Nakhon Nayok rain water & 6.81 & 40 & 1 & 90 & 63 \\
\hline Chachoengsao tap water & 6.75 & 15 & 0 & 70 & 66 \\
\hline Nakhon Nayok tap water & 6.82 & 1 & 0 & 50 & 31 \\
\hline Bangkok tap water \#1 & 6.66 & 10 & 0 & 80 & 102 \\
\hline Bangkok tap water \#2 & 7.04 & 1 & 0 & 80 & 77 \\
\hline Bottled purified water \#1 & 6.87 & 10 & 0 & 80 & 26 \\
\hline Bottled purified water \#2 & 7.11 & 10 & 0 & 110 & 118 \\
\hline Bottled purified water \#3 & 6.74 & 1 & 0 & 50 & 26 \\
\hline Local bottled mineral water \#1 & 6.82 & 10 & 0 & 110 & 26 \\
\hline Local bottled mineral water \#2 & 6.75 & 1 & 1 & 150 & 210 \\
\hline Local bottled mineral water \#3 & 6.78 & 15 & 1 & 180 & 122 \\
\hline Imported bottled mineral water \#1 & 6.53 & 25 & 1 & 230 & 350 \\
\hline Imported mineral water \#2 & 7.02 & 10 & 1 & 210 & 252 \\
\hline Sport drink \#1 & 6.82 & 65 & 10 & 670 & 26 \\
\hline Sport drink \#2 & 6.89 & 60 & 10 & 590 & 26 \\
\hline Thailand Tap Water Standard ${ }^{\dagger}$ & $6.5-8.5$ & 15 & 5 & 500 & 300 \\
\hline
\end{tabular}

\footnotetext{
$\dagger$ in agreement with WHO $2011^{15,16}$.
} 
Table 2 The mineral concentrations of water.

\begin{tabular}{|c|c|c|c|c|c|c|c|c|}
\hline \multirow[t]{2}{*}{ Source of water } & \multicolumn{8}{|c|}{ Concentration $(\mathrm{mg} / \mathrm{l})$} \\
\hline & $\mathrm{Na}^{+}$ & $\mathrm{K}^{+}$ & $\mathrm{Cl}^{-}$ & $\mathrm{HCO}_{3}^{-}$ & $\mathrm{Mg}^{2+}$ & $\mathrm{Ca}^{2+}$ & $\mathrm{PO}_{4}^{-}$ & $\mathrm{Fe}^{3+}$ \\
\hline Chachoengsao dug well & 253 & 20 & 603 & 305 & 29 & 56 & ND & 0.28 \\
\hline Nakhon Nayok dug well & ND & ND & 177 & ND & 13 & 43 & 8 & 0.54 \\
\hline Chachoengsao canal & 207 & 31 & 461 & 305 & 47 & 54 & 7 & 0.11 \\
\hline Nakhon Nayok canal & ND & ND & ND & ND & 6 & 14 & 5 & 0.23 \\
\hline Chachoengsao artesian water & 276 & 20 & 638 & 366 & 22 & 56 & ND & 0.18 \\
\hline Nakhon Nayok artesian water & ND & ND & ND & 488 & 5 & 13 & 14 & 0.27 \\
\hline Chachoengsao rain water & ND & ND & ND & 366 & ND & 26 & ND & 0.11 \\
\hline Nakhon Nayok rain water & ND & ND & ND & ND & ND & 25 & ND & 0.48 \\
\hline Chachoengsao tap water & ND & ND & ND & ND & ND & 26 & ND & 0.14 \\
\hline Nakhon Nayok tap water & ND & ND & ND & ND & ND & 12 & 6 & 0.03 \\
\hline Bangkok tap water \#1 & ND & ND & ND & ND & 3 & 36 & ND & 0.35 \\
\hline Bangkok tap water \#2 & ND & ND & ND & ND & 1 & 29 & ND & ND \\
\hline Bottled purified water \#1 & ND & ND & ND & 488 & ND & ND & 8 & 0.17 \\
\hline Bottled purified water $\# 2$ & ND & ND & ND & 366 & 5 & 39 & 8 & 0.16 \\
\hline Bottled purified water \#3 & ND & ND & ND & ND & ND & ND & 7 & ND \\
\hline Local bottled mineral water \#1 & ND & ND & ND & 488 & ND & ND & 8 & 0.20 \\
\hline Local bottled mineral water \#2 & ND & ND & ND & 427 & 5 & 76 & 15 & ND \\
\hline Local bottled mineral water \#3 & ND & ND & ND & 366 & 6 & 39 & 8 & 0.28 \\
\hline Imported bottled mineral water \# 1 & ND & ND & ND & 427 & 14 & 117 & ND & 0.54 \\
\hline Imported mineral water \#2 & ND & ND & ND & 427 & 17 & 73 & 6 & 0.11 \\
\hline Sport drink \#1 & 943 & 149 & 1205 & ND & ND & ND & ND & 0.23 \\
\hline Sport drink \#2 & 851 & 172 & 1347 & ND & ND & ND & ND & 0.18 \\
\hline Thailand Tap Water Standard ${ }^{\dagger}$ & & & 250 & & & $100-300$ & & 0.3 \\
\hline
\end{tabular}

$\mathrm{ND}=$ non-detectable

${ }^{\dagger}$ in agreement with WHO $2011^{15,16}$.

cides widely used in the agricultural fields and from washing powders in the wastewater runoff. The artesian water is a ground water. It was partly protected from surrounding environment by the pipe wall, and thus it was clearer than the surface water. The artesian water was fairly yellow and had substantial iron contents. Their TDS, hardness, and mineral components were similar to that of surface water from the same province, which, according to a previous report ${ }^{21}$, should have derived not only from lithogenic origin but also from pollutants closely related to adjacent polluted surface water. The water from Nakhon Nayok had a high amount of phosphate, which might be a result of chemical fertilizers and pesticides used in the farm lands. Rain water samples were slightly acidic feasibly because they reacted with gaseous acidic pollutants ${ }^{22}$. Their calcium contents ought to have arrived from contamination of calcium dust pollutants in the atmosphere ${ }^{23}$. Nakhon Nayok rain water was stored in a metal tank covered by a metal lid, thus its high iron concentration should have come from the corroded metal tank or lid as reported ${ }^{19,24}$.
Tap water is the treated surface water and, in Thailand, its quality must be compliant with the WHO water quality standard guideline ${ }^{15}$. From Table 1, the tap water samples were slightly acid which might be a result of ion removal in the treatment process ${ }^{25,26}$. The tap water from Nakhon Nayok had a negligible amount of iron because it was collected from a newly constructed building with a new plumbing system. Likewise, tap water from one building in Bangkok had no iron detected because at the time when water was collected, the pipeline in that building was wholly changed from metal to polyvinyl chloride. Two other samples were yellowish relating with their iron contents. The results advocate that the amounts of iron in tap water should mainly come from corroded aged metal pipe in the houses or the status of residential plumbing system ${ }^{11}$. Phosphate in the Nakhon Nayok tap water was detected which might relate to widely chemical fertilizers and pesticide used in the farms. Some people mistrust the purity of tap water and prefer to spend money on bottled purified water which is believed to be safer, cleaner, and of 
better taste than tap water ${ }^{1}$. Regarding the mineral contents, the bottled purified water sample \#2 had nothing different from tap water. Moreover, phosphate, which was mostly undetected in tap water, was detected in all bottled waters which should be added from bottle cleansing agents and if they were improperly stored; phosphate might have come from dissolved bottle plastic. Iron was detected in samples \#1 and \#2 which might have derived from the corroded metal pipe or container used in the water treatment or packaging. Ion removal can cause water to be more aggressive in seeking for ion replacement including iron from the aged cast iron pipes $^{25,26}$, thus filtration or reverse osmosis may enhance iron dissolution from a corroded metal pipe. Bottled mineral water is the ground water expected to contain high amounts of natural minerals ${ }^{27,28}$ especially calcium and magnesium. Inasmuch as there is a negative association between incidence of cardiovascular disease and the amounts of calcium and magnesium intake, the bottled mineral water has been promoted as a supplementary contribution to calcium and magnesium intake ${ }^{29}$. From Table 2, the domestic bottled mineral water \#1 had no detectable calcium or magnesium. The results from imported bottled mineral water support previous reports ${ }^{30,31}$ that the amount of minerals in some European bottled mineral water was lower than indicated on the labels. Sport drink is also promoted as a mineral supplement. Unlike the bottled mineral water, chemical substances can be added to the sport drink. They were amber yellow but did not correlate with their small iron amounts, therefore, their colour might come from an additive substance. Both had pleasant odour and salty sweet taste due to addition an aromatic compound, sugar, and salt to serve the consumers' favour. Because they had high amounts of $\mathrm{NaCl}$, drinking them may unnecessarily increase sodium intake to a level that may be detrimental to health, especially for individuals on a sodium restricted diet ${ }^{31}$. Bottled water, particularly mineral water, and sport drinks are costly, however, their quality and health benefit may not justify their price. In fact, some are identical to the tap water. Normally, individuals receive nutrient minerals mainly from dietary foods. Drinking water containing high levels of calcium, magnesium, and potassium can be crucial in the prevention of magnesium deficiency ${ }^{5,32}$ as well as contribute significantly to the daily calcium and potassium intake for persons with calcium or potassium-deficient diets ${ }^{10,33-35}$.

\section{REFERENCES}

1. Gorelick MH, Gould L, Nimmer M, Wagner D, Heath M, Bashir H, Brousseau DC (2011) Perceptions about water and increased use of bottled water in minority children. Arch Pediatr Adolesc Med 165, 928-32.

2. Ward LA, Cain OL, Mullally RA, Holliday KS, Wernham AGH, Baillie PD, Greenfield SM (2009) Health beliefs about bottled water: a qualitative study. $B M C$ Publ Health 9, 196.

3. Saleh MA, Abdel-Rahman FH, Woodard BB, Clark S, Wallace C, Aboaba A, Zhang W, Nance JH (2008) Chemical, microbial and physical evaluation of commercial bottled waters in greater Houston area of Texas. $J$ Environ Sci Health A 43, 335-47.

4. Diduch M, Polkowsk Ż, Namieśnik J (2013) Factors affecting the quality of bottled water. $J$ Expo Sci Environ Epidemiol 23, 111-9.

5. Yang CY (1998) Calcium and magnesium in drinking water and risk of death from cerebrovascular disease. Stroke 29, 411-4.

6. Nerbrand C, Agréus L, Lenner RA, Nyberg P, Svärdsudd K (2003) The influence of calcium and magnesium in drinking water and diet on cardiovascular risk factors in individuals living in hard and soft water areas with differences in cardiovascular mortality. BMC Publ Health 3, 21.

7. Rylander R, Arnaud MJ (2004) Mineral water intake reduces blood pressure among subjects with low urinary magnesium and calcium levels. BMC Publ Health 4, 56.

8. Garzon P, Eisenberg MJ (1998) Variation in the mineral content of commercially available bottled waters: implications for health and disease. Am J Med 105, 125-30.

9. Nagata C, Takatsuka N, Shimizu N, Shimizu H (2004) Sodium intake and risk of death from stroke in Japanese men and women. Stroke 35, 1543-7.

10. Stolarz-Skrzypek K, Bednarski A, Czarnecka D, Kawecka-Jaszcz K, Staessen JA (2013) Sodium and potassium and the pathogenesis of hypertension. Curr Hypertens Rep 15, 122-30.

11. Sarin P, Snoeyink VL, Bebee J, Kriven WM, Clement JA (2001) Physico-chemical characteristics of corrosion scales in old iron pipes. Water Res 35, 2961-9.

12. Si YB, Wang SQ, Chen HM (2000) Agricultural nitrogen and phosphorus loss and eutrophication. Soils 4, 188-93, [in Chinese].

13. Oguz E, Gurses A, Yalcin M (2003) Removal of phosphate from waste waters by adsorption. Water Air Soil Pollut 148, 279-87.

14. de-Bashan LE, Bashan Y (2004) Recent advances in removing phosphorus from wastewater and its future use as fertilizer (1997-2003). Water Res 38, 4222-46.

15. World Health Organization (2011) Guidelines for Drinking-Water Quality, 4th edn, WHO, Geneva, 
Switzerland.

16. Sobsey MD, Bartram S (2003) Water quality and health in the new millennium: the role of the World Health Organization Guidelines for DrinkingWater Quality. In: Elmadfa I, Anklam E, König J (eds) Modern Aspects of Nutrition: Present Knowledge and Future Perspectives, Forum of Nutrition Vol. 56, Karger, Basel, Switzerland, pp 396-405.

17. American Public Health Association (1999) Standard Methods for the Examination of Water and Wastewater, American Water Works Association, Water Environment Federation, New York, NY.

18. Subba Rao N, Surya Rao P, Venktram Reddy G, Nagamani M, Vidyasagar G, Satyanarayana NLVV (2012) Chemical characteristics of groundwater and assessment of groundwater quality in Varaha River Basin, Visakhapatnam District, Andhra Pradesh, India. Environ Monit Assess 184, 5189-214.

19. Ritter L, Solomon K, Sibley P, Hall K, Keen P, Mattu G, Linton B (2002) Sources, pathways, and relative risks of contaminants in surface water and groundwater: a perspective prepared for the Walkerton inquiry. $J$ Toxicol Environ Health A 65, 1-142.

20. Edet A, Worden RH (2009) Monitoring of the physical parameters and evaluation of the chemical composition of river and groundwater in Calabar (Southeastern Nigeria). Environ Monit Assess 157, 243-58.

21. Wahaab RA, Badawy MI (2004) Water quality assessment of the River Nile system: an overview. Biomed Environ Sci 17, 87-100.

22. Panyakapo M, Onchang R (2008) A four-year investigation on wet deposition in western Thailand. J Environ Sci 20, 441-8.

23. Salve PR, Maurya A, Wate SR, Devotta S (2008) Chemical composition of major ions in rainwater. Bull Environ Contam Toxicol 80, 242-6.

24. Sarin P, Snoeyink VL, Bebee J, Jim KK, Beckett MA, Kriven WM, Clement JA (2004) Iron release from corroded iron pipes in drinking water distribution systems: effect of dissolved oxygen. Water Res $\mathbf{3 8}$, 1259-69.

25. Taylor J, Dietz J, Randall A, Hong S (2005) Impact of RO-desalted water on distribution water qualities. Water Sci Tech 51, 285-91.

26. Cerrato JM, Reyes LP, Alvarado CN, Dietrich AM (2006) Effect of PVC and iron materials on Mn(II) deposition in drinking water distribution systems. Water Res 40, 2720-6.

27. US, Environmental Protection Agency (1992) Draft Ground Water Disinfection Rule, Office of Drinking Water, US EPA, Washington, DC.

28. International Bottled Water Association (2012) Bottled Water Code of Practice, IBWA, Alexandria, VA.

29. Galan P, Arnaud MJ, Czernichow S, Delabroise AM, Preziosi P, Bertrais S, Franchisseur C, Maurel M, et al (2002) Contribution of mineral waters to dietary calcium and magnesium intake in a French adult population. J Am Diet Assoc 102, 1658-62.

30. Misund A, Frengstad B, Siewers U, Reimann C (1999) Variation of 66 elements in European bottled mineral waters. Sci Total Environ 243-244, 21-41.

31. Azoulay A, Garzon P, Eisenberg MJ (2001) Comparison of the mineral content of tap water and bottled waters. $J$ Gen Intern Med 16, 168-75.

32. Rylander R, Bonevik H, Rubenowitz E (1991) Magnesium and calcium in drinking water and cardiovascular mortality. Scand J Work Environ Health 17, 91-4.

33. Aaron KJ, Sanders PW (2013) Role of dietary salt and potassium intake in cardiovascular health and disease: a review of the evidence. Mayo Clin Proc 88, 987-95.

34. Karppanen H, Karppanen P, Mervaala E (2005) Why and how to implement sodium, potassium, calcium, and magnesium changes in food items and diets? J Hum Hypertens 19, S10-9.

35. Yang Q, Liu T, Kuklina EV, Flanders WD, Hong Y, Gillespie C, Chang MH, Gwinn M, et al (2011) Sodium and potassium intake and mortality among US adults: prospective data from the third national health and nutrition examination survey. Arch Intern Med 171, 1183-91. 